\title{
CONSUMO DE FRUTOS DE Prunus sellowii Koehne (ROSACEAE) POR AVES EM UM FRAGMENTO FLORESTAL EM JUNDIAÍ, SP
}

\author{
Maria Aparecida Masteguin \\ Faculdade de Ciências e Letras \\ Associação Padre Anchieta de Ensino - Jundiaí - SP \\ Rodolfo Antônio de Figueiredo \\ PG-Ecologia, Instituto de Biologia \\ Universidade Estadual de Campinas - Campinas - SP
}

\section{RESUMO}

Aspectos ecológicos das espécies animais e vegetais que ocorrem em fragmentos florestais são pouco conhecidos. O presente estudo teve o objetivo de caracterizar a guilda de aves visitantes de Prumus sellowii Koehne em frutificação. Foi verificado grande número de indivíduos consumindo os frutos, mas pertencentes a apenas 5 espécies ( 3 gêneros) de aves. A atividade destas aves se reveste de importância na disseminação das sementes da espécie vegetal para outros fragmenios e para áreas que sofreram influência antrópica.

\section{SUMMARY}

Masteguin, M.A. \& Figueiredo, R.A.de. Fruit consumption of Prumus sellowii Koehne (Rosaceae) in a forest fragment in Jundiai, SP

Ecological aspects of animal and plant species which occur in forest fragments are poorly known. This study intended to characterize the guild of bird species visiting a Prumus sellowii Koehne showing mature fruits. A great number of individuals consumed the fruits, but only 5 species ( 3 genera) of birds were recorded. The activity of these birds is important to disseminate seeds of the plant to other forest remnants and to areas modified by humans. 


\section{INTRODUÇÃO}

$\mathrm{O}$ interior do estado de São Paulo sofreu intenso desmatamento, mas ainda existem remanescentes florestais de pequeno porte dispersos pelas propriedades rurais. Esta cobertura florestal na pequena propriedade é importante para a proteção do solo contra a erosão e o aumento da retenção de água ${ }^{1}$. Apesar da alta diversidade florística das matas semidecíduas do planalto paulista ${ }^{2}$, poucos estudos ecológicos são desenvolvidos nestes fragmentos. Os aspectos ecológicos de espécies vegetais e animais que habitam fragmentos florestais são praticamente desconhecidos ${ }^{3,4}$.

O presente estudo teve como objetivo verificar a frugivoria por aves em frutos do pessegueiro-do-mato (Prunus sellowii), uma espécie arbórea importante para recomposição de áreas degradadas ${ }^{5}$, e avaliar a importância das aves na dispersão de suas sementes.

\section{MATERIAL E MÉTODOS}

O trabalho de campo foi desenvolvido no município de Jundiai (aproximadamente $\left.23^{\circ} 11^{\prime} \mathrm{S} ; 46^{\circ} 52^{\prime} \mathrm{W}\right)$, em um sítio utilizado para plantio de árvores frutiferas, principalmente pêssego, e a área de mata nativa remanescente atinge aproximadamente 18,5 ha.

Prunus sellowii, popularmente conhecida como pessegueiro-do-mato, é uma árvore nativa de aproximadamente 10-15 metros de altura, que cresce tanto no interior como na borda de matas pluviais e semideciduas. Os frutos são drupas arredondadas, carnosas, atro-purpúreas, medindo cerca de $11,5 \mathrm{~mm}(\mathrm{~N}=10)$, contendo uma única semente. $\mathrm{Na}$ área de estudo, esta era a única espécie arbórea a apresentar frutos maduros no final de julho, sendo que anteriormente à esta data ocorreu a frutificação do tamanqueiro (Aegiphila sellowiana, Verbenaceae) e da anona (Annona cacans, Annonaceae). As observações das aves foram feitas em agosto e setembro de 1995, entre 7:00 e 18:00h (24h de observação no total). No periodo de estudo a quantidade estimada de frutos na árvore foi de 4500 .

As observações foram feitas a uma distância de 1 a 5 metros da árvore, utilizando-se binóculo $7 \times 35 \mathrm{~mm}$. Todas as espécies de aves visitantes foram anotadas, assim como a ocorrência ou não da ingestão dos frutos, o número, o horário e a duração das visitas, além do comportamento das diversas espécies ao consumirem os frutos. As espécies de aves foram identificadas seguindo Frisch ${ }^{6}$. 


\section{RESULTADOS}

A frutificação do pessegueiro-do-mato estendeu-se do final de julho ao final de setembro. Treze espécies de aves visitaram a planta. Destas, cinco espécies consumiram efetivamente os frutos e oito apenas pousaram na árvore. As aves que consumiram frutos permaneceram na árvore de 15 a 120 segundos, voando para longe da mesma. Os frugivoros mais freqüentes foram Turdus spp. (sabiás) e Pitcingus sulphuranıs (bem-te-vi) (Tabela 1).

TABELA 1. Aves que visitaram Prumus sellowii em um fragmento florestal de Jundiai, SP.

\begin{tabular}{llcc}
\hline \hline Nome científico & Nome popular & Ingere frutos & $\mathbf{N}^{\circ}$. de visitas \\
\hline Turdus amaurochalimus & Sabiá-pardo & $\mathrm{X}$ & 254 \\
Turdus lencomelas & Sabiá-branco & $\mathrm{X}$ & 84 \\
Turdus rufiventris & Sabiá-laranjeira & $\mathrm{X}$ & 24 \\
Mimus saturninuss & Sabiá-do-campo & $\mathrm{X}$ & 02 \\
Pitangus sulphuratus & Bem-te-vi & $\mathrm{X}$ & 24 \\
Euphonia sp. & Vivi & & 03 \\
Cyanocompsa cyanea & Azulão & & 02 \\
Sporophila caerulescenss & Coleirinho & & 01 \\
Molotrus bonariensis & Chopim & & 05 \\
Tyranmus savana & Andorinhão & & 03 \\
Nemosia pileata & Fruteiro & & 03 \\
Piaya cayana & Alma-de-gato & & 01 \\
Guira guira & Anu-branco & & 01 \\
\hline
\end{tabular}

O comportamento de manipulação dos frutos pelas espécies de sabiás era o de engolir os frutos inteiros ("swallow whole", segundo Moermond \& Denslow "). Cada indivíduo ingeria de 3 a 5 frutos por visita e saia da árvore. O método de pegar os frutos, apresentado pelos sabiás, foi o de capturar enquanto pousado ("perched position" ${ }^{7}$ ), pegando os frutos próximos ao pouso ("picking" 7 )

O bem-te-vi apresentou o comportamento de engolir os frutos inteiros, e o comportamento de captura foi o de pegar os frutos em vôo, planando com as asas abertas ("wing position" e "swooping" 7). Estas aves ingeriram de 2-4 frutos por visita.

As visitas à procura dos frutos eram mais intensas nos horários das 7:00 às 9:00h e das 16:00 às 18:00h (Figura 1). Nestes horários foram observados encontros agressivos intraespecíficos entre indivíduos de Turdus amaurochalimus (13 ocasiões), e encontros agressivos 
interespecíficos entre Pitangus sulfuratus e Turdus amaurochalimus e entre Turdus leucomelas e $T$. amaurochalinus (4 ocasiões).

\section{Número de Indivíduos.}

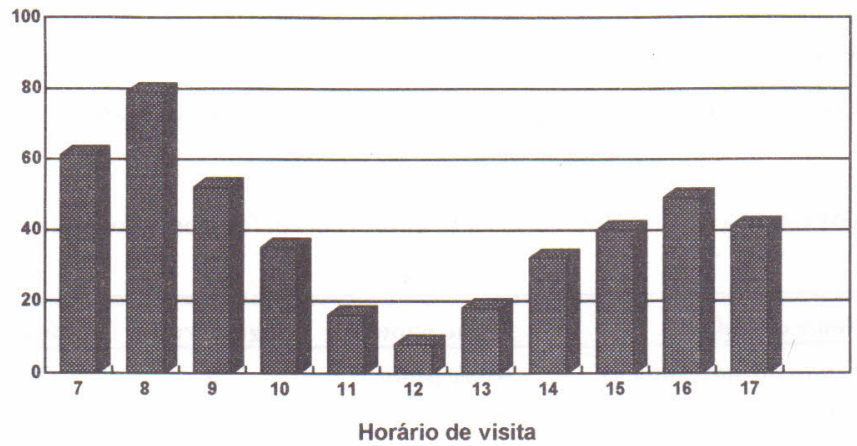

FIGURA 1. Número de indivíduos consomem frutos de Prumus sellowii por horário de visita, em Jundiai, SP.

\section{DISCUSSÃO}

A maioria das visitas foi de Turdus spp. O grande número de indivíduos observados, representando poucas espécies de aves, provavelmente se deve ao empobrecimento da avifauna neste fragmento florestal. $\mathrm{O}$ isolamento dos remanescentes de mata nativa provocam uma concentração da fauna nestes locais, aumentando a competição interespecífica e resultando na saturação do fragmento por poucas espécies ${ }^{3}$. O grande número de encontros agressivos intraespecíficos também é um indicativo de saturação ${ }^{8}$.

As espécies que consumiram os frutos podem ser consideradas dispersoras das sementes, pois engoliam o fruto inteiro e ficavam pouco tempo na árvore ${ }^{9}$. O comportamento de engolir o fruto inteiro é limitado pela largura do bico da ave ${ }^{7}$, reduzindo o número de espécies capazes de consumir os frutos de Prumus sellowii. As larguras dos bicos dos sabiás, que está entre 12,5 e $13,5 \mathrm{~mm}$, e a do bem-te-vi, ca. $16,5 \mathrm{~mm}$, são maiores que o diâmetro dos frutos do pessegueiro-do-mato. Moermond \& Denslow ${ }^{7}$ sugeriram que um bico muito mais largo que o fruto permite a sua ingestão por aves em vôo, tal como foi observado para o bem-te-vi, mas aves com larguras de bico próximas ao tamanho do fruto, como é o caso dos sabiás, ingerem os frutos 
enquanto pousadas. Portanto, os resultados deste estudo estão de acordo com esta sugestão presente na literatura ${ }^{7}$. O padrão comportamental verificado garante que as sementes sejam disseminadas longe da árvore-mãe, diminuindo a chance de predação ${ }^{10}$. Tanto os sabiás como o bem-te-vi foram observados utilizando os mesmos comportamentos de consumo e captura ao utilizarem frutos de uma figueira ${ }^{11}$. Motta-Junior \& Lombardi ${ }^{12}$ também encontraram sabiás e bemte-vis como os principais dispersores da copaiba, e Motta-Junior ${ }^{13}$ verificou que sabiás são as aves mais frequentemente encontradas em matas do interior do estado de São Paulo. Silva ${ }^{14}$ verifico que as espécies de aves que se alimentam de uma cactácea na Serra do Japi (municipio de Jundiai apresentam, assim como o verificado no presente trabalho, maior atividade nas primeiras horas di manhã

A presença do pessegueiro-do-mato no fragmento é importante pois esta espécie oferece importante recurso alimentar para as aves, particularmente para os sabiás. As aves frugivoras que pousaram na árvore sem consumirem seus frutos, provavelmente não o fizeram pelo tamanho do fruto ser maior que o da largura do bico ${ }^{15}$. Portanto, $P$. sellowii também é importante para aves que procuram pouso para observação dos arredores, descanso, procura de insetos ou abrigo contra predadores ${ }^{16}$

A dispersão das sementes de espécies florestais por elementos da fauna com alta mobilidade, como é o caso das aves, é importante na regeneração de outros fragmentos florestais ${ }^{3} \mathrm{e}$ de áreas que, após serem utilizadas por seres humanos, foram abandonadas ${ }^{17}$.

\section{AGRADECIMENTOS}

Os autores agradecem ao Sr. José Nani por permitir o estudo em sua propriedade, a J. C. Motta-Junior por ceder material bibliográfico, e a dois revisores anônimos por leitura crítica e valiosas sugestões à uma versão preliminar do manuscrito.

\section{BIBLIOGRAFIA CITADA}

1. ANGELO, H. Cobertura florestal na pequena propriedade rural: uma aiternativa para o desenvolvimento. Brasil Florestal, 61 : 37-41. 1987.

2. LEITÃO-FILHO, H. F. A flora arbórea da Serra do Japi. In: L. P. C. Morellato (org.) História Natural da Serra do Japi. Ed. Unicamp/Fapesp, Campinas, pp. 40-62. 1992. 
3. ESTRADA, A.; COATES-ESTRADA, R; MERITT JR., D; MONTIEL, S \& CURIEL, D. Patterns of frugivore species richness and abundance in forest islands and in agricultural habitats at Los Tuxtlas, Mexico. Vegetatio, 107/108: 245-257. 1993.

4. MOREllato, L. P. C. \& LEITÃO-FILHO, H. F. Ecologia e Preservação de uma Floresta Tropical Urbana. Ed. Unicamp, Campinas, SP, 136pp. 1995.

5. LORENZI, H. Árvores Brasileiras. Ed. Plantarum, Nova Odessa, SP, pp. 300. 1992.

6. FRISCH, J. D. Aves Brasileiras. Dalgas-Ecoltec Ecologia Técnica, São Paulo, 353pp. 1981.

7. MOERMOND, T. C. \& DENSLOW, J. S. Neotropical frugivores: patterns of behaviour, morphology and nutrition with consequences for fruit selection. In: P. A Buckley, M. S. Foster, E. S. Morton, R. S. Ridgely \& N. G. Buckley (eds.) Neotropical Ornithology. A.O.U. Monographs number 36, American Ornithologists' Union, Washington, pp. 865-897. 1985.

8. MARCONDES-MACHADO, L. O. \& ARGEL-DE-OLIVEIRA, M. M. Comportamento alimentar de aves em Cecropia (Moraceae), em Mata Atlàntica, no estado de São Paulo. Revista Brasileira de Zoologia, 4: 331-339. 1988

9. FLEMING, T. H.; VENABLE, D. L. \& HERRERA M., L. G. Opportunism vs. specialization: the evolution of dispersal strategies in fleshy-fruited plants. Vegetatio, 107/108: 107-120. 1993.

10. JANZEN, D. H. Herbivores and the number of tree species in tropical forests. American Naturalist, 104: 501-528. 1970.

11. FIGUEIREDO, R. A. de; MOTTA-JUNIOR, J. C. \& VASCONCELLOS, L. A. S. Pollination, seed dispersal, seed germination and establishment of seedlings of Ficus microcarpa, Moraceae, in southeastern Brazil. Revista Brasileira de Biologia, 55: 233-239. 1995.

12. MOTTA-JUNIOR, J. C. \& LOMBARDI, J. A. Aves como agentes dispersores da copaiba (Copaifera langsdorffii, Caesalpiniaceae) em São Carlos, estado de São Paulo. Ararajuba, 1: 105-106. 1990.

13. MOTTA-JUNIOR, J. C. Estrutura trófica e composição das avifaunas de três hábitats terrestres na região central do estado de São Paulo. Ararajuba, 1: 65-71. 1990.

14. SILVA, W. R. Ornitocoria em Cereus peruvianus (Cactaceae) na Serra do Japi, estado de São Paulo. Revista Brasileira de Biologia, 48: 381-389. 1988.

15. MOTTA-JUNIOR, J. C. \& FIGUEIREDO, R. A. de. Influência da largura do bico e do peso corporal de passeriformes na taxa de consumo de sementes de Micheliachampaca (Magnoliaceae). Biotemas, 8: 110-118. 1995.

16. ARGEL-DE-OLIVEIRA, M. M. \& FIGUEIREDO, R. A. de. Aves que visitam uma figueira isolada em ambiente aberto, no estado do Espírito Santo, Brasil. Inheringia, in press.

17. LOMBARDI, J. A. \& MOTTA-JUNIOR, J. C. Levantamento do subbosque de um reflorestamento monoespecífico de Pinus elliottii em relação as síndromes de dispersão. Turrialba, 42: 438-442. 1992. 